\title{
Case Report: \\ RETROGRADE APPROACH FOR CTO LESIONS: SERIAL CASE
}

\author{
Yudi Her Oktaviono \\ Department of Cardiology, Faculty of Medicine \\ Dr. Soetomo Hospital, Surabaya
}

\begin{abstract}
ABSTRAK
Total oklusi rekanalisasi kronik masih merupakan batas akhir dalam intervensi koroner perkutan. Kesuksesan revaskularisasi dikaitkan dengan peningkatan kelangsungan hidup jangka panjang, pengurangan gejala, peningkatan fungsi ventrikel kiri dan pengurangan kebutuhan untuk operasi bypass koroner. Retrograde total oklusi rekanalisasi kronis baru-baru ini menjadi pelengkap penting untuk pendekatan antegrade klasik. Pendekatan retrograde melalui saluran agunan telah diusulkan baru-baru ini dan memiliki potensi untuk meningkatkan tingkat keberhasilan intervensi koroner perkutan (PCI) dalam total oklusi (CTO) lession kronis arteri koroner. Kami melaporkan beberapa kesusksesan kasus prosedur rekanalisasi CTO menggunakan pendekatan retrograde di Rumah Sakit Soetomo. (FMI 2016;52:296-304)
\end{abstract}

Kata kunci: jumlah oklusi kronis, intervensi koroner perkutan, CTO rekanalisasi, pendekatan retrograde.

\begin{abstract}
Chronic total occlusion recanalization still represents the final frontier in percutaneous coronary intervention. Successful revascularization is associated with improved long-term survival, reduced symptoms, improved left ventricular function and reduced need for coronary bypass surgery. Retrograde chronic total occlusion recanalization has recently become an essential complement to the classic antegrade approach. Retrograde approach through the collateral channel has been recently proposed and has the potential to improve the success rate of percutaneous coronary intervention (PCI) in chronic total occlusion (CTO) lesion of the coronary arteries. We report several cases of successful CTO recanalization procedure using retrograde approach in Soetomo Hospital. (FMI 2016;52:296-304)
\end{abstract}

Keywords: chronic total occlusion, percutaneous coronary intervention, CTO recanalization, retrograde approach.

Correspondence: Yudi Her Oktaviono, Department of Cardiology, Faculty of Medicine, Airlangga University, Dr. Soetomo Hospital, Surabaya.

\section{INTRODUCTION}

Chronic Total Occlusion (CTO) of coronary artery is a major challenge and a dilemma unsolved in the field of interventional cardiology. In the community of cardiologists, there are still doubts about the indications of PCI in CTO and there is still skepticism about the results done on a CTO revascularization (Mario 2007). Prevalence CTO of all patients who underwent coronary angiography varies between $18 \%-52 \%$ depending on the clinical profile of patients examined (Ardaji et al 2014). There is great variability in the data on CTO treated with percutaneous coronary intervention (PCI). In North America incidence of CTO was from 29-33\%, only $6-9 \%$ treated with PCI (Ardaji et al, 2014, Srivinas 2002). While in Japan of a $19 \%$ incidence of CTO, $61.2 \%$ were treated with PCI (Ardaji et al, 2014, Mehran 2011).

Many studies mention that CTO recanalization may provide benefits in increased life expectancy and the patient's prognosis. Successful CTO PCI in addition to improving clinical symptoms, also improves quality of life, left ventricular function and life expectancy and reduce the number of CABG (Mario 2007).

Antegrade technique is an engineering approach that was first selected in most PCI CTO. But in most cases, the wire fails to penetrate the CTO in antegrade manner. Retrograde technique to penetrate the CTO of the distal portion through a collateral branch is predicted to be able to increase the success rate of PCI in coronary artery CTO lesions (Mario 2007). Data from a multicenter study in Japan say that the retrograde technique was performed on $26 \%$ of the total cases of CTO (3014 cases). Of the 801 cases of CTO, in a retrograde technique success rate in crossing guidewire was $82.3 \%$ (669) (Okamura 2012). In this case report we reported some patients with $\mathrm{CTO}$ revascularization undergoing successful PCI with retrograde technique. 


\section{CASE REPORT}

\section{Case 1}

Ms. S, female, 62 years old, came to the hospital for elective coronary angiography. Patients presented with clinical presentation of stable angina. The risk factors were hypertension and diabetes. ECG showed sinus rhythm $90 \mathrm{x} / \mathrm{min}$, normal axis. Laboratory results were within normal limits with SK 1.2. Echocardiographic results were obtained MR, PR was moderate, dilated left atrium, left ventricle and right ventricle with decreased left ventricular function (EF 45\%), abnormal diastolic dysfunction of relaxation, as well as inferoseptal hypokinetic, and eccentric $\mathrm{LVH}$.

CHD coronary angiography results obtained TVD with CTO in mid RCA, 90\% stenosis in the proximal LAD, $80 \%$ stenosis in the proximal $\mathrm{Cx}$ and $70 \%$ in the distal Cx. Syntax score of 23. The patient refused to do surgery and chose PCI. We performed predilatation with balloons Jive $2.0 \times 20 \mathrm{~mm}$ and ballon Maverick $2.0 \times 12$ $\mathrm{mm}$, proceeded with the installation DES stent Promus 2:25 x $18 \mathrm{~mm}$ at the proximal LCX and Cypher Select stent DES 2:25 x $18 \mathrm{~mm}$ at the distal Cx overlapping with the proximal stent. Attempt to penetrate the CTO in RCA failed.

Furthermore, one month after elective PCI was performed at RCA. Attempt to penetrate the CTO was done with retrograde technique. Effort began by entering the EBU GC 3.5 7F in GC 4.0 6F LMCA and RCA through the femoral artery in the right and left. Septal collateral channels of LAD to the RCA (CC2) were observed. Then it was followed by entering wire Fielder FC 180 with support Corsair 2.6F microcatheter 150 of LAD through collateral to the RCA. Sign Fielder wire microcatheter 180 with support from RCA 1352.6 Corsair tried to break in mid RCA CTO. But the effort to penetrate the CTO of antegrade was unsuccessful. CTO finally penetrated with Fielder FC wire from LAD retrograde and kissing in mid RCA with the wire of the RCA. Wire Fielder FC was later replaced with a wire RG3 to get out of the GC JR. Furthermore, predilatation was done with balloons Ryujin $2.0 \times 20 \mathrm{~mm}$ at the RCA after microcatheter Corsair remov-ed. Do Nobori DES stenting $2.5 \times 28 \mathrm{~mm}$ at the mid-distal RCA and Nobori DES stent $2.75 \times 28$ at the proximal-mid RCA and Nobori DES stent $3.0 \times 18 \mathrm{~mm}$ in osteal-proximal RCA. We performed post-dilatation with Ex stent balloon. The final result was good. During and after the action we did not obtain complications.

\section{Case 2}

Mr. RS, male, aged 60 years, had stable angina. The patient was hospitalized due to heart attack and pulmonary edema 7 months previously. The patient had never underwent cardiac catheterization and stent was installed six months ago. The risk factors were dyslipidemia and smoking. During this time the patient had optimal medical therapy, namely clopidogrel, aspirin, simvastatin, ISDN. Current clinical condition, complaints of chest pain was not obtained. Physical examination found BP $110 / 70 \mathrm{~mm} \mathrm{Hg}$, pulse $75 \mathrm{x} / \mathrm{min}$, ictus cordis shifted $1 \mathrm{~cm}$ lateral mid-clavicular line (MCL) of the left. Examination of the thoracic obtained cardiomegaly CTR of $60 \%$. The results ECG of sinus rhythm $75 \mathrm{x} / \mathrm{min}$ showed axis deviation to the left, and a long anterior inferior myocardial infarction. Results catheterization 6 months ago: Long LAD lesion proximal-distal disease with a maximum of $90 \%$ stenosis in the proximal LAD, Cx: $70 \%$ stenosis in the proximal Cx, RCA: CTO in the proximal RCA. Syntax Score 37 . The patient refused to do bypass surgery and chose PCI. DES stenting performed E-Magic Plus 2.75 x 15 and Stent DES Biomime $3.0 \times 32 \mathrm{~mm}$ at the proximal-distal LAD. Conclusion: CHD TVD post PTCA stent in the LAD. Then we underwent cardiac catheterization again four months later with the following results: Left main normal, LAD showed patent old stent in the proximal-distal, LCX non dominant with stenosis significant $70 \%$ in the proximal, CC2 epicardial collateral canal was observed from distal LCx toward the distal RCA, RCA dominant, CTO was apparent in proximal RCA.

Then it was decided to revascularization PCI CTO in RCA. GC catheter inserted EBU $3.57 \mathrm{~F}$ in LMCA ostium and JR GC $4.06 \mathrm{~F}$ at the ostium of the RCA through the right and left femoral artery. We noted CC2 epicardial collateral profile from LCx to the RCA. Antegrade technique was used to open CTO using wire runthrough NS hypercoat. CTO was penetrated. Furthermore, we did Poba with balloons acrostak grip $2.5 \times 16 \mathrm{~mm}$ and balloon Mozec $1.5 \times 9 \mathrm{~mm}$ at the proximal RCA, but failed to break through the distal balloon occlusion.

The attempt was followed by retrograde technique with incoming wire run through NS hypercoat through GC EBU 3.5 7F toward the distal Cx. Wire runthrough with support microcatheters Finecross entered through collateral branch distal to the distal RCA $\mathrm{Cx}$ and continued until the distal of the CTO. Furthermore, wire runthrough NS hypercoat replaced with wire Miracle. Wire miracle with suport microcatheters Finecross encouraged to enter GC JR. Next go wire runthrough NS hypercoat back of the proximal RCA and do predilatasi with balloons mozec $1.5 \times 9 \mathrm{~mm}$ balloon acrostak grip $2.5 \times 16 \mathrm{~mm}$ at the proximal to the distal 
RCA. Obtained complications of dissection in the mid RCA. Then do stenting DES Firebird 2 (rapamycin) 3.0 x $33 \mathrm{~mm}$ at the proximal-mid RCA and Firebird DES stent 2 (rapamycin) $2.75 \times 29 \mathrm{~mm}$ in mid RCA are overlapping. Residual stenosis in RCA $0 \%$, did not seem dissection in RCA. Enterprises followed by stenting DES Firebird 2 (rapamycin) 3.5 x $18 \mathrm{~mm}$ proximal-distal $\mathrm{Cx}$ are direct stenting. Residual stenosis in $\mathrm{Cx} 0 \%$.

\section{Case 3}

TB, male, 46 years old came to the hospital for elective coronary angiography. Patients present with clinical presentation of stable angina. The risk factors were smoking and diabetes. ECG showed sinus bradycardia rhythm 58x/minute, old myocardial infarction and ischemia anteroseptal inferior. Laboratory results were within normal limits with SK 1.0. Examination of thoracic images shape and size showed the heart within normal limits. Results obtained echocardiographic left ventricular function decrease (EF 53\%), abnormal diastolic dysfunction of relaxation, as well as hypokinetic anteroseptal and inferior left ventricle.

CHD coronary angiography results obtained TVD with CTO in the proximal RCA, diffuse disease in LAD, Cx OM branched long lesion. Syntax score of 41 . However, patients either refused revascularization with $\mathrm{CABG}$ or PCI. Because of chest pain that appears more and more often, one week later the patient agree to do an elective PCI. We performed predilatation with balloons Brio 2.5 x $20 \mathrm{~mm}$ and Nobori DES stenting $2.5 \times 2.0 \mathrm{~mm}$ in the mid LAD and Nobori DES stent $3.0 \times 28 \mathrm{~mm}$ at the proximal-mid LAD. OM2 branch dilatation in $\mathrm{Cx}$ with balloons Ryujin Plus 1:25 x $15 \mathrm{~mm}$ then mounted stent Endeavor DES (zotarolimus) 2:25 x $30 \mathrm{~mm}$ at the branch OM2 Cx. Attempt to penetrate the CTO in RCA failed.

The next five months later we performed elective PCI at RCA. Attempt to penetrate the CTO was done with retrograde technique. The effort started by entry GC JR $4.06 \mathrm{~F}$ in the RCA through the right radial artery, as well as GC EBU $3.57 \mathrm{~F}$ in LMCA through long $7 \mathrm{~F}$ sheath through the left femoral artery. Septal collateral channels (CC2) of LAD to the RCA was observed. CTO penetrate effort by using wire Fielder Microcatheter Corsair FC with the support of the LAD through septal collateral to the distal CTO in RCA. The attempt to penetrate CTO was successful. Wire Fielder FC replaced with wire microcatheters Corsair RG3 with support and encouraged to enter GC JR. Microcatheters Corsair pulled out. Furthermore dilatation balloon Ryujin Plus $2.0 \times 15 \mathrm{~mm}$ in antegrade. Then we performed Nobori DES stenting $2.5 \times 28 \mathrm{~mm}$ at the proximal RCA and stent DES Endeavour 2:25 x $30 \mathrm{~mm}$ at the proximal-mid RCA. When wire RG3 was to be pulled out with difficulty (entrapment device), so we used microcatheters Corsair back to help remove the wire RG3. The final result was good. Residual stenosis was $0 \%$.

\section{Case 4}

Mr T, male, 64 years old came to the hospital for elective coronary angiography. Patients present with clinical presentation of stable angina. The risk factors were hypertension and diabetes. ECG shows sinus rhythm 90x/minute, normal axis. Laboratory results were within normal limits with SK 0.9.

Patients already been done mounting ring two months ago. The results of coronary angiography is currently obtained CHD DVDs with CTO in osteal LAD, long stent in the artery patent-mid intermediate and proximal RCA. Planned retrograde strategy for CTO recanalization in the LAD because the previous attempt to penetrate CTO PCI in antegrade failure.

The action begins with the entrance GC JL 4.0 7F in LMCA through the right femoral artery and JR GC 4.0 $6 \mathrm{~F}$ at the RCA through the left femoral artery. Looks collateral septal CC1 of RCA to the LAD. Furthermore, wire Fielder FC 180 and 150 microcatheters Corsair 2.6F sign of RCA via septal collateral distal to the proximal LAD CTO. Wire Fielder FC later replaced by GW Miracle 3. Log wire runthrough NS hypercoat in antegrade of GC JL. GW retrograde Miracle 3 managed to penetrate the CTO and kissing with antegrade GW runthrough NS hypercoat. Furthermore miracle GW 3 is replaced by RG3 with suport microcatheters Corsair pushed forward to get into the GC JL. Furthermore, RG3 and microcatheters Corsair withdrawn until the distal RCA. GW runthrough NS hypercoat of GC JL inserted to the distal LAD. Furthermore, do predilatasi with balloons Ryujin $2.0 \times 20 \mathrm{~mm}$ in osteal-proximal LAD. Do Nobori DES stenting 3.0 x $18 \mathrm{~mm}$ in ostealproximal LAD. We performed post-dilatation Ex stent balloon. The final result is good.

\section{DISCUSSION}

CTO is defined as the presence of TIMI (Thrombolysis in Myocardial Infarction) flow grade of 0 in a segment that is experiencing occlusion, and estimated age of the occlusion is more than or equal to three months. The duration of occlusion is determined from the interval from the first heart attack according to the location of the occlusion or of the results of previous angiography (Mario 2007). 
CTO has highly variable clinical presentation. Patients with CTO may appear with the presentation of stable angina, silent ischemia, heart failure due to ischaemia, while on the other hand there are CTO patients who are discovered accidentally. The benefits of the opening of the artery occlusion are, among others, improvements of angina complaints, an increase in left ventricular function, avoid bypass surgery as well as increasing life expectancy (Kalnins 2013, George 2014).

Considerations for CTO recanalization do have to take into account the clinical history, test results provocative sensitive non-invasive, coronary anatomy, as well as the experience of CTO recanalization operator. Indications of CTO recanalization was the same with indications on the stenotic lesion is that when angina or ischemia are obtained caused by arterial territories that experienced CTO (Kalnins 2013, Saito 2008, Windecker et al 2014). In patients with no symptoms or symptoms controlled by medication, it is important to do a sensitive noninvasive provocation test for the presence of ischemic area (Mario 2007). CTO with myocardial necrosis were already at the distal lesion revascularization performed PCI because the action will not provide a lot of changes (Kalnins 2013, Saito 2008, Windecker et al 2014).

CTO recanalization options may be catheterization and surgical procedures. Surgical options CTO recanalization was done if the CTO with left main disease or CTO with multiple vessel disease (Shah 2011). Several models of risk stratification that focuses on the complexity of the anatomy, clinical risk can also be used to help make decisions (Windecker et al 2014). SYNTAX score is made to determine the degree of complexity of coronary artery lesions in patients with left main or three-vessel disease and is a predictor of long-term cardiac as well as the occurrence of adverse cardiovascular events (Windecker et al 2014). In a post hoc analysis of the results of the SYNTAX study at 4 years was found that the presence of CTO is the strongest independent predictor of incomplete revascularization and provides clinical adverse effect on the output, including mortality (Windecker et al 2014).

When the CTO recanalization has been performed percutaneously, we need to use gradually PCI strategy on multi-vessel disease to avoid a very long procedure and the amount of contrast. Selection of action sequences, CTO or non CTO should be done first, must be based on the importance of blood vessel lesions. When the blood vessels and the number of viable myocardium was more important in the area, the CTO CTO recanalization was done first. But when poor flow of contralateral or planned retrograde technique, the contralateral blood vessels can be opened first. We should consider the opportunities of failure and success case by case in selecting strategy (Mario 2007).

Some parameters that can be a predictor of a decreased level of successful CTO recanalization procedures are listed in Table 1.

Table 1. Characteristics of lesions and patient influential in the success of recanalization (Mario 2007)

\begin{tabular}{lcc} 
& Simple & Complex \\
\hline Vessel diameter (mm) & $>3.0$ & $<3.0$ \\
Occlusion length $(\mathrm{mm})$ & $\leq 20$ & $>20$ \\
Calcium occluded segment & None to moderate & Severe \\
Tortuosity occluded segment & Minimal to moderate & Severe \\
Occlusion stump & Tapered & Blunt or absent \\
Distal vessel opacification & Good to excellent & Poor \\
Distal vessel disease & Absent or moderate & Severe \\
Tandem/multiple occlusions & No & Yes \\
Tortuosity proximal to occlusion & Minimal to moderate & Severe \\
Disease of the proximal segment & Absent or Moderate & Severe \\
Expected guiding catheter support & Good & Poor \\
Ostial location & No & Yes \\
Previous attempts & No & Yes* \\
Renal insufficiency & Yes & No \\
Expected patient tolerance & Good & Poor \\
\hline
\end{tabular}

Some scores can be used to predict the success of PCICTO include J-CTO and SYNTAX score focus on evaluation of CTO lesion (Sys-CTO score). Of one study comparing the Sys-J-CTO CTO and found that JCTO better provide the predictive value of success CTO recanalization procedure compared Sys-CTO (Tanabe et al 2013).

Table 2. J-CTO Scores (Morino et al 2011)

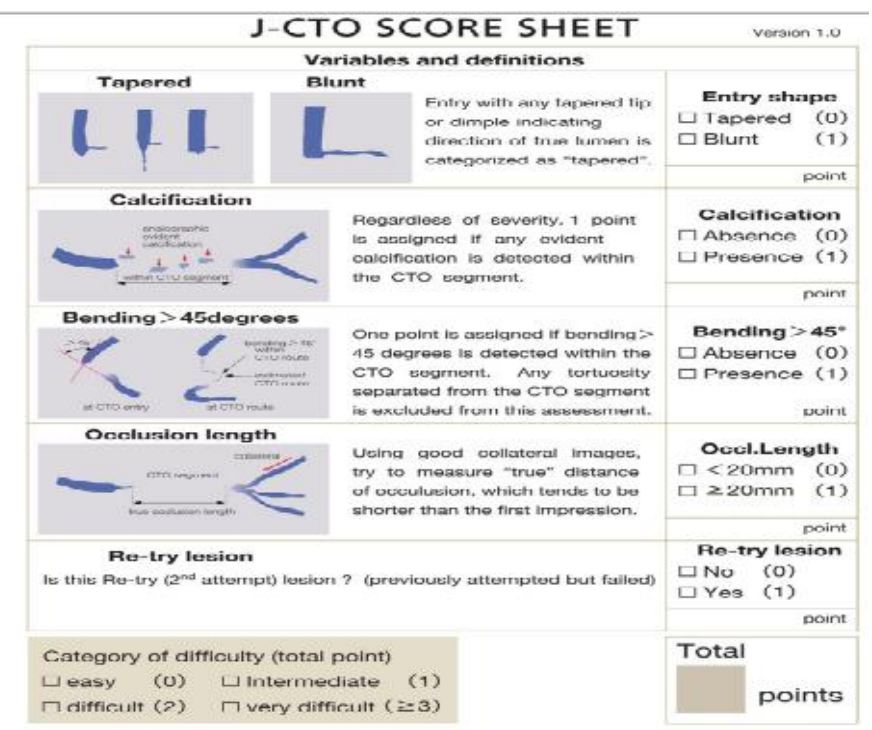


Th guidelines mention that if the CTO lesion cannot be penetrated within 30 minutes since the insertion sheath then the procedure is stopped. If the total duration of the procedure was 90 minutes and the contrast or the total exceeds $300 \mathrm{ml}$ procedures were also suspended. However, standard time of guideline may be exceeded if the estimated chance to penetrate the large and CTO angioplasty of the lesion is considered essential to avoid the operation (Saito, 2008).

Retrograde technique is an approach to CTO recanalization by inserting a wire through a collateral branch artery that connects the target coronary arteries with arterial lesions CTO (Saito, 2008). Data from a multicenter in Japan, 801 cases of CTO conducted retrograde technique success rate guidewire and cathter to penetrate collateral channels by $82.3 \%$ and $76.2 \%$ (Okamura 2012). Meta-analyzes of other studies mention the success rate of the procedure amounted to $83.3 \%$ retrograde technique (Sabbagh 2014). Retrograde recanalization is an advanced technique that requires special skills and should be done by an interventionist advanced level (Kimura 2012).

In general retrograde technique should not be used as a first choice and is usually used after antegrade technique failure. In certain cases, retrograde technique can be used as the first choice when it antegrade wiring technique seems difficult because of anatomical factors (Kalnins 2013, Windecker et al 2014).

\section{Mechanical retrograde $\mathrm{PCI}$ in CTO lesions}

Filming of angiography and collateral channels analyzer

The first step that needs to be done is filming angiography and collateral channels analyzer (CC). In retrograde technique, long CTO lesions have to be estimated, although it is not a predictor of failure occurred as the antegrade technique. Collateral channels need to be evaluated by double injection. Adequate contrast injection flow and multiple angle shooting is very important to get information about the collateral sources and to maximize the image obtained. Other information that should be explored include the size of the blood vessels distal to the lesion, the estimated amount of myocardial damage, calcification, the side branches as well as the morphology of the proximal and distal CTO. The distal portion CTO gets a stream of collateral with a lower pressure than the proximal portion of the CTO is to get the flow of systemic diastolic blood flow, so that the distal CTO have softer characteristics and forms that are easier to penetrate. Therefore, if obtained predictor factor CTO recanalization failure then retrograde technique can be used to increase success in the CTO (Joyal 2012).
Preparatory actions

Double arterial access is essential in retrograde approach. Arterial access approach can be done with a combination of one radial 1 femoral, bilateral femoral, bilateral or transradial. Selection of which approach is used depends on the choice and experience of the operator as well as the risks and benefits of each approach. Bilateral transradial approach was associated with lower risk of bleeding as well as patient comfort, while transfemoral approach allows the operator to use a catheter with a larger diameter (eg $7 \mathrm{~F}$ or $8 \mathrm{~F}$ ). Short guiding catheter use is strongly recommended in retrograde approach. Retrograde approach often led to deep engagement on a guiding catheter after externalization. Guiding catheter $90 \mathrm{~cm}$ (commercially available size $6 \mathrm{~F}, 7 \mathrm{~F}$ and $8 \mathrm{~F}$ ) allows for externalization wire without worrying about the length of the catheter (Joyal 2012). $90 \mathrm{~cm}$ guiding catheter (Launcher, Medtronic, USA) EBU-SH for the left coronary artery and SAL-SH for the right coronary artery is widely used for the retrograde technique (Saito, 2008). Can also be used guiding catheter with a shortened regular $100 \mathrm{~cm} 10 \mathrm{~cm}$ manually introducer sheath is then connected to the smaller size of 1F (Joyal 2012). Strategies to reduce bleeding are important for CTO recanalization using unfractionated heparin doses greater than usual. The use of heparin is recommended during CTO recanalization compared bivalirudin or inhibitors of GPIIb/IIIa for nature reversibility (Joyal 2012).

\section{Selection of collateral channels}

Analysis of collateral channels is essential in retrograde technique. There are two types of septal and epicardial collateral channels (CC). Septal CC should have a relatively straight. Factors turtousity be a limitation in the choice of septal CC compared to the size factor. While the selection of epicardial $\mathrm{CC}$ more by size and not tortousity, because epicardial CC almost always turtous. Septal CC is the safest and should be selected as the top choice for Septal CC perforation usually causes no hemodynamic disturbances or tampo-nade and can usually close spontaneously (Joyal, 2012, Kern 2013). Of RAO projection (right anterior oblique) cranial, septal CC connecting coronary artery LAD (left anterior descending) artery with PDA (posterior descending artery) was shaped like the letter B (Joyal 2012). Epicardial CC traditionally among others: distal LAD and PDA, and a diagonal branch of the LAD, distal Cx and PL (posterolateral) (Joyal 2012).

Visualization collateral channels can be done by nonselective contrast injection through the guiding catheter. However, this method usually provides better visualization of the distal less. Selective contrast 
injection through a catheter corsairs were positioned at the proximal septal collateral channels will provide a good visualization. Contrast injection should not be done at the distal canal septal collateral due to the risk of septal rupture so that the collateral channel unusable and causing septal hematoma (Joyal 2012).

In contrast to the septal collateral channels, the collateral channel surfing epicardial is not necessary, because the wire has been formed beforehand to follow the canal path collateral. Out of the path may lead to perforation, perforation of the canal where the collateral epicardial more dangerous than the perforation of the septal collateral channels. Sion Guidewire (Asahi Intecc) has been widely used by carriers in Europe and in Japan with a high success rate and low number perforation. Channel collateral turtous epicardial often lose their shape while after crossing the Corsair microcatheters, where it can trigger ischemia. Therefore epicardial collateral channel is the last option that is chosen to avoid the occurrence of ischemia (Joyal 2012).

There are several groupings degree collateral channels. In this paper we consider grouping based classification Werner for use in retrograde technique and can predict ischemia based on the size of the collateral channels. Based on its size, collateral channels can be stratified into 3 degrees. $\mathrm{Cc} 0$, does not seem a connection between an artery donor and recipient artery, CC1, looked thin continuous connection, $\mathrm{CC} 2$, looked connection between arteries donor and recipient artery with measures such as blood vessels branch. For the estimation of measurement can use the electronic calipers: $\mathrm{CC} 1$ diameter? $0.3 \mathrm{~mm}$ and $\mathrm{CC} 2$ ? $0.4 \mathrm{~mm}$. $\mathrm{Cc} 0$ and canals winding collateral associated with the risk of failure of the procedure (Werner et al 2003).

Access and collateral channels crossing

The first step is to position the guidewire Floppy (Runthrough ${ }^{\circledR}$ or runthrough-Hypercoat ${ }^{\circledR}$, Terumo) until it reaches the selected collateral channels, microcatheters then positioned in the proximal part of the collateral channel. Furthermore guidewire replaced with polymer-coated guidewire or plastic-jacket hydrophilic guidewire to traverse the canal collateral. Guidewire commonly selected to down the canal collateral among others Fielder ${ }^{\circledR}$, Fielder FC ${ }^{\circ}$ (Asahi Intecc), Pilot $50 \AA$, Whisper-LS ${ }^{\circledR}$ or MS ${ }^{\circledR}$ (Abbott Vascular, Santa Clara, California) and guidewire with more pointed ends like Fielder XT® (Asahi Intecc). Hydrophilic guidewire tip is bent usually $30-45 \mathrm{o}$ at $1 \mathrm{~mm}$ from the distal end.

Currently microcatheters choice for retrograde technique is Corsair catheter (Asahi Intecc). Corsair is a type of catheter over the wire comprising hydrophilic consisting of 8 thin wires with 2 wires thicker and serves as collateral canal dilator. As an alternative can also be used as Terumo FineCross ${ }^{\circledR}$ microcatheters (Terumo, Sommerset, New Jersey) or Supercross (Vascular Solutions, Minneapolis, Minnesota), Progreat ${ }^{\circledR}$ or Finecross ${ }^{\circledR}$ (Terumo, Japan), Transit $\AA$ (Cordis, USA). The use of this microcatheters besides cheaper than microcatheters korsair, can also be reused for antegrade technique (Saito 2008, Joyal 2012).

Guidewire is then directed to reach the recipient artery. Guidewire advanced by far enough to provide sufficient support to the placement microcatheters Corsair. This is done by movement clockwise and counterclockwise rotation. Microcatheters then positioned until it reaches the distal part of occlusion. In cases where collateral channels are very turtous, microcatheters may be difficult to be rotated or pushed further. In such circumstances the usual rotation counterclocwise more effectively while microcatheters pushed forward. If that does not work although it has been tested with both directions of rotation, it can be replaced with a new microcatheters. If the new microcatheters still unable to penetrate the right collateral, may be replaced with a balloon catheter (Ryujin ${ }^{\circledR}-\mathrm{OTW}$ 1:25 x $10 \mathrm{~mm}$, Terumo, Lacross ${ }^{\circledR} 1: 30 \times 10 \mathrm{~mm}$, Goodman, Japan or Maverick ${ }^{\circledR}-\mathrm{OTW} 1: 50 \times 15 \mathrm{~mm}$, Boston Scientific, USA ) by using a guidewire extension. If the channel is collaterals used septal collateral channels, dilatation in all segments with low pressure $(<4 \mathrm{~atm})$ to prevent catheter clamping. When the balloon microcatheters and still can not penetrate the collateral channels, can be used catheters Tornus ${ }^{\circledR}$ (ASAHI Intecc). After successfully passing through the canal collateral catheter, guidewire and then replaced with a guidewire Miracle ${ }^{\circledR 3}$ (Miracle 3: ASAHI Intecc) (Saito 2008, Joyal 2012).

\section{Crossing CTO (Saito, 2008)}

After the retrograde guidewire is replaced by the Miracle 3, do the penetration of the distal part of the CTO. If the CTO is still deemed too hard to be penetrated with the Miracle 3 guidewire can be replaced with a more rigid tip as Miracle 6 or 12 or ConquestPro ${ }^{\circledR}$ or Conquest-Pro 12 (ASAHI Intecc). After successfully penetrate retrograde $\mathrm{CTO}$, do one or a combination of the following strategies:

Kissing Guidewire. If the distal end of the CTO is soft enough to penetrate, retrograde guidewire can be met by end of antegrade guidewire. Just Landmark. Although the retrograde guidewire tip can be met with a guidewire antegrade, retrograde guidewire still used as 
markers (landmarks) to antegrade guidewire manipulation. This technique can reduce exposure contrast.

Controlled antegrade and etrograde subintimal Tracking (CART) and Reverse CART. CART method is to menginsersikan subintimal space of the balloon in the retrograde guidewire then the balloon is dilated so that there is enough place for antegrade guidewire lumen to reach the distal section. And conversely reverse engineering to insert CART is the balloon from the antegrade guidewire subintimal space then dilated then performed penetration of retrograde guidewire.

Retrograde True Lumen Tracking. The distal portion of the CTO sometimes very turtous but did not appear despite the injection of contrast. This makes it difficult to track the true lumen in antegrade. In this case hidrophilic retrograde guidewire can be used to find hidden paths turtous.

True Lumen Proximal Retrograde Puncture. Guidewire retrograde $\mathrm{CTO}$ of the distal portion penetrating toward true lumen of the proximal CTO. Then dilatation balloon at CTO lesions were inserted retrograde. Guidewire Floppy then inserted from the proximal portion of the lumen distal to the CTO.

Cathching The Retrograde Guidewire. If the retrograde technique puncture occurs proximal true lumen dissection after balloon dilatation, then no guidewire that can penetrate the lesion antegrade. In such cases may be used technique cathing the retrograde guidewire. In this technique retrograde guidewire pushed forward until it reaches the antegrade guiding catheter, is then inserted through the guidewire microcatheters. Guidewire subsequently replaced with floppy guidewire 300CM Rotablator ${ }^{\circledR}$. Guidewire rotablator then driven to reach the end of the distal part antegrade guiding catheter, then captured manually. The balloon then inserted antegrade toward CTO lesions through retrograde guidewire. The use guidewire rotablator important because the smaller diameter.

Wiring antegrade, snaring and externalization (Joyal 2012)

If the occlusion has been penetrated, eg after kissingwire technique, the procedure is then performed with wire antegrade and retrograde instruments issued. Immediately after microcatheters or over-the-wire balloon catheter or by antegrade tornus successfully passed CTO, antegrade guidewire needs to be replaced with safer guidewire.
In most retrograde technique, managed to penetrate the retrograde wire lumen proximal to the occlusion. At this stage directed towards the wire retrograde antegrade guiding catheter. If possible microcatheters Corsair also advanced to penetrate the occlusion. Tether end of the wire in the GC retrograde antegrade using antegrade balloon (anchoring technique with a balloon on the GC $7-8 \mathrm{~F} 2.5 \mathrm{~mm}$ or $2.0 \mathrm{~mm}$ on the $6 \mathrm{~F} \mathrm{GC}$ ) can give a pretty good support to advance microcatheters Corsair to penetrate the occlusion. If this fails, Corsair can be replaced with balloons over-the-wire $1.5 \mathrm{~mm}$ or $1: 25$ having a crossing profile of less than Corsair's CTO retrograde dilatation. If this step is successful, it will usually begin to appear antegrade flow and antegrade wire can then be forwarded to the distal arteries.

The next step is the externalization. Wire retrograde previously managed to penetrate the occlusion pulled out and replaced with a long wire inserted retrograde until it reaches the hemostatic valve with the aim to transform into in antegrade recanalization procedure. If the retrograde wire has reached the aorta, the wire is replaced with a wire length of $300 \mathrm{~cm}$ so that the end of the wire to do snaring. Some long wire that can be used for externalization include Pilot $200(300 \mathrm{~cm})$, floppy wire Rotablator $(325 \mathrm{~cm})$, wire ViperWire Advance $(335 \mathrm{~cm})$. Snare usable 3-loop snare En 18-30 mm Endovascular System (Merit Medical Systems, South Jordan, Utah). Snare En compatible standards among other measures $6 \mathrm{~F}$ and $7 \mathrm{~F}$. Antegrade wire is pulled up in the aorta is positioned above the distal portion of the wire retrograde. Wire retrograde is then advanced until it enters into one of 3 loops, then captured and towed to GC antegrade. GC antegrade then positioned back into the coronary ostium. During the phase of externalization great pressure on the GC retrograde occurs primarily because during the process can occur deep seating.

The opening of the occlusion

Microcatheters Corsair pulled up to the distal portion of the artery, and the balloon is inserted through the wire of guiding antegrade retrograde already externalization to penetrate the occlusion. After occlusion successfully penetrated, there are two selection steps. The first choice is followed by the development process of the balloon and stent through retrograde wire externalization. The second option, the development process of the balloon and stent performed on antegrade wire inserted in the occlusion that is already open. After antegrade wire position is correct, confirmed on contrast injection contralateral, microcatheters Corsair forwarded to wire near GC antegrade retrograde until then wire microcatheters Corsair retrograde along slowly withdrawn and removed (Joyal 2012). 
Table 3. Complications retrograde technique and management (Kimura 2012)

\begin{tabular}{|c|c|c|c|c|c|}
\hline \multicolumn{2}{|c|}{ Complications } & \multirow{2}{*}{$\frac{\mathbf{N} \text { (total 41) }}{36}$} & \multicolumn{3}{|c|}{ Treatment $(\mathrm{N})$} \\
\hline Perforation: & $\begin{array}{l}\text { Septal channel }(\mathrm{N}-20) \\
\text { Epicardial channel }(\mathrm{N}=14) \\
\text { Coronary artery }(\mathrm{N}=2)\end{array}$ & & & & \\
\hline Class I & & 23 & Observation (23) & & \\
\hline Class II & & 10 & $\begin{array}{l}\text { Reversal of } \\
\text { anticoagulation (8) }\end{array}$ & $\begin{array}{l}\text { Embolization with } \\
\text { fat tssue or coll (2) }\end{array}$ & Balloon inflation $(6)$ \\
\hline Class IIICS & & 0 & & & \\
\hline Class III & & 3 & Cardiocontosis (3) & Balloon infiation (3) & Stentimplantation (1) \\
\hline \multicolumn{2}{|c|}{ Myocardial ischemia } & 4 & & & \\
\hline \multicolumn{2}{|c|}{ Thrombus injection from donor artery } & 1 & Aspiration (1) & Balloon intlation (1) & \\
\hline \multicolumn{2}{|c|}{ Micro-catheter in collateral } & 3 & Stentimplantation (1) & Balloon inflation (3) & \\
\hline \multicolumn{2}{|c|}{ Device stuck in coronary artery } & 1 & Emergency CABG (1) & & \\
\hline \multicolumn{2}{|c|}{ Cardiac Death } & 0 & & & \\
\hline
\end{tabular}

Abbreviations; Class I, extraluminal crater without extravasation; Class II, pericardial or myocardial blushing; Class III, perforation > or = 1- $\mathrm{mm}$ diameter with contrast streaming; and cavity spilling

CABG; coronary artery bypass graft

\section{Making the final image}

In making the final image to be evaluated, patency of blood vessels that are already open and the damage that may occur in collateral channels should be noted. Staining contrast to the septal collateral channels is common but rarely provide hemodynamic disturbances (Joyal 2012).

\section{Complications in retrograde technique}

Complications that can occur in engineering retrograde include perforation of collateral, perforation coronary dissection of blood vessels donor, complications of vascular access, tamponade, nefropathy contrast, myocardial infarction, stroke, wire broken, the tool is stuck (device entrapment) (Sabbagh 2014, Kimura 2012). Security procedures with manipulation wire careful and proper management of complications is needed in retrograde technique.

\section{CONCLUSION}

Retrograde technique could be an alternative approach to engineering the CTO lesion, but should be used after antegrade technique failure. Retrograde technique must be performed by an experienced operator in handling CTO and have been able to perform retrograde technique independently. Complications in retrograde technique are more common than conventional techni- ques, so it needs to be anticipated and handled with suitable management.

\section{REFERENCES}

Ardaji, A., J.R. Lopez, and M.T. Sanchez, Chronic total occlusion: treat or not to be treat. World J Cardiol, 2014. 6(7): p. 621-629.

George, S., Long-Term Follow-Up of elective Chronic Total Coronary Occlusion Angioplasty. J Am Coll Cardiol, 2014. 64: p. 235-243.

Joyal, D., The Retrograde Technique for Recanalization of Chronic Total Occlusions: A step-by-step approach. J Am Coll Cardiol Intv, 2012. 5: p. 1-11.

Kalnins, A., Chronic total coronary artery occlusion recanalization with percutaneous coronary intervention using anterograde and retrograde approach - Riga East Clinical University Hospital Experience. Acta chirurgica latviensis, 2013. 13: p. 17-21.

Kern, M., ed. Interventional Cardiac Catheterization Handbook. 3 ed. Percutaneous Coronary Intervention of Chronic Total Occlusions, ed. Uretsky and M. Maradeh. 2013.

Kimura, M., Management of procedural complication related to percutaneous corornary intervention of chronic total occlusion via the retrograde approach. JACC, 2012. 59(13): p. e108.

Mario, C., European perspective in the recanalisation of chronic total occlusion (CTO): consensus document 
from the EuroCTO Club. EuroInterv, 2007. 3: p. 3043.

Mehran, R., Long-term outcome of percutaneous coronary intervention for chronic total occlusions. J Am Coll Cardiol Intv, 2011. 4: p. 952-961.

Morino, Y., et al., Predicting Successful Guidewire Crossing Through Chronic Total Occlusion of Native Coronary Lesions Within 30 Minutes The J-CTO (Multicenter CTO Registry in Japan) Score as a Difficulty Grading and Time Assessment Tool. J Am Coll Cardiol Intv, 2011. 4: p. 213-221.

Okamura, A., A report from japanese multicentre registry data for clinical results of retrograde approach in percutaneous coronary interventions for chronic total occlusions. JACC, 2012. 59(13): p. e293.

Sabbagh, A., Angiographic success and procedural complication in patients undergoing retrograde percutaneous coronary chronic total occlusion interventions: a weigted meta-analysis of 3482 patients from 26 studies. Int J Cardiol, 2014. 174(2): p. 243-248.

Saito, S., Different Strategies of Retrograde Approach in Coronary Angioplasty for Chronic Total Occlusion.
Catheterization and Cardiovascular Interventions, 2008. 71: p. 8-19.

Shah, P.B., Management of Coronary Chronic Total Occlusion. Circulation, 2011. 123: p. 1780-1784.

Srivinas, V., Contemporary percutaneous coronary intervention versus ballon angioplasty for multivessel coronary artery disease. A comparison of the NHLBI dynamic registry and BARI study. Circulation, 2002. 106: p. 1627-1633.

Tanabe, M., K. Asada, and T. Yagi, TCT-363 Can the SYNTAX Score Focused on the Evaluation of Chronic Total Occlusion(CTO) be a Useful Predictor of Successful Revascularization in CTO-PCIs?; Comparison with the J-CTO Score. J Am Coll Cardiol, 2013. 62(18_s1): p. B115-B115.

Werner, G.S., et al., Angiographic Assessment of Collateral Connections in Comparison With Invasively Determined Collateral Function in Chronic Coronary Occlusions. Circulation, 2003. 107: p. 19721977.

Windecker, S., et al., 2014 ESC/EACTS Guideline on Myocardial Revascularization. European heart journal, 2014. 